\title{
MARGARITA RUANO, OBRAS DRAMÁTICAS INÉDITAS: BAILE DEL JUEGO DE VUELEN PAJARITOS, BAILE DE VENENO DE LOS SENTIDOS, BAILE DE LOS TÍTULOS DE COMEDIAS
}

JuAna Escabias

Dramaturga

escabiasjuana@gmail.com

\section{RESUMEN}

En este artículo editamos tres obras desconocidas de Margarita Ruano, dramaturga del siglo XVII. Los manuscritos se descubrieron durante una investigación en la que se buscaban los datos biográficos básicos sobre esta escritora, acerca de la que no poseíamos informaciones de ningún tipo.

Palabras Clave: Ruano. Teatro Siglo Oro. Dramaturga española. Baile.

\section{Abstract}

In this article we published three works unknown of Margarita Ruano, playwright seventeenth century. The manuscripts were discovered during an investigation that sought basic biographical data on this writer, about which we did not have information of any kind.

KEY WORDS: Ruano. Golden Century Theatre. Spanish playwright. Dance.

No sabemos nada acerca de Margarita Ruano. Su nombre aparece recogido por Miguel Herrero García, historiador, periodista y crítico literario que nació en Málaga 
en el año 1895 y pasó la mayoría de su vida en Madrid, donde falleció en 1961. Herrero publicó numerosos libros y trabajos relacionados con el Siglo de Oro, entre ellos una colección de artículos en los que compilaba diversas piezas teatrales de autores de esa época protagonizadas por enclaves de Madrid (plazas, calles, fuentes, edificios, etc.) La colección fue publicada de forma fragmentada en la Revista de Archivos Bibliotecas y Museos del Ayuntamiento de Madrid entre 1925 y 1929. Una de las piezas seleccionadas fue el Baile de las posadas de Madrid, firmado por Margarita Ruano, sobre la que el autor no aportaba ni una sola información. El manual Autoras en la Historia del Teatro Español se hizo eco de esa publicación, y citó el Baile de las posadas de Madrid y a su autora, añadiendo que «no ha sido posible encontrar ningún dato de esta autora, excepto su nombre en ese manuscrito. Ignoramos por tanto si es autora de otras obras teatrales». (Hormigón, 1996, 595-596) El nombre Margarita Ruano no aparece recogido por Manuel Serrano y Sanz, ni por Nicolás Antonio, ni por Cayetano de La Barrera... Ni uno solo de los especialistas dedicados a la historia de la literatura femenina o al teatro antiguo la mencionan en sus manuales. La circunstancia nos hizo sospechar. ¿Se trataba de un pseudónimo? ¿Podía ser un error?

Un manuscrito fechado en 1692 que pudimos localizar y cotejar y que contenía el Baile de las posadas de Madrid aparecía atribuido, efectivamente, a Margarita Ruano. Emprendimos una investigación en busca de datos biográficos sobre la autora que de momento no ha cosechado frutos, pero en ese trabajo de indagación hallamos tres piezas dramáticas firmadas por Margarita Ruano que no habían sido mencionadas anteriormente por ningún otro investigador. Esas obras eran: Baile del Juego de Buelen Pajaritos (de 1692), Baile de beneno de los sentidos (de 1700) y Vayle de los títulos de comedias (de 1690).

La aparición de estos tres manuscritos nos permite hablar ya con propiedad de la existencia de Margarita Ruano como personaje histórico y de su actividad continuada como dramaturga (el Baile del Juego de Buelen Pajaritos está fechado el mismo año que el Baile de las posadas de Madrid), actividad extendida como mínimo a lo largo de diez años. Su quehacer aparece concentrado en la ciudad de Madrid y vinculado de manera firme a la escena madrileña de la época: tanto el manuscrito del Baile de las posadas de Madrid como el del Vayle de títulos de comedias poseen los correspondientes permisos de la Censura para ser representados. En la primera pieza ese permiso se otorga sin condiciones, en la segunda se exige que sean eliminados varios versos. Son pocos datos sobre este personaje, pero bastante más de lo que conocíamos antes del descubrimiento de las tres piezas. Mientras continuamos la investigación biográfica sobre Margarita Ruano, publicamos estos tres bailes en verso polimétrico, considerando el valor que poseen como hallazgo para la historia de los estudios sobre literatura española en su vertiente dramática.

Nuestra edición ha modernizado la grafía, adaptándola a nuestra época. Por cuestiones de espacio no nos extenderemos en explicaciones sobre la naturaleza y características de esa forma de teatro breve que es el baile. En la transcripción se ha respetado la estructura rítmica original de los manuscritos. 
BAILE DEL JUEGO DE VUELEN PAJARITOS

Margarita Ruano. Madrid, 1692.

PERSONAJES: La Diversión. La Desconfianza. El Respeto. La Libertad. El Amor. La Ingratitud. La Sinrazón. El Favor. El Olvido.

Sale LA DIVERSIÓN cantando.

LA DIVERSIÓN.-

LA DESCONFIANZA.-

EL RESPETO.-

LA LIBERTAD.-

EL AMOR.-

LA DIVERSIÓN.-

LA INGRATITUD.-

LA DIVERSIÓN.-

LA SINRAZÓN.-

LA DIVERSIÓN.-

LA DESCONFIANZA.-

LA DIVERSIÓN.-

EL FAVOR.-

LA DIVERSIÓN.-

EL OLVIDO.-

LA DIVERSIÓN.-

TODOS.-

EL RESPETO.-

EL AMOR.-
Pues he de representar

el primer día hoy, venía

para que dé al tiempo,

víctimas, la adoración.

Yo os llamo, yo os busco; venid a mi voz.

De cuantos juegos compone

la alegre, festiva, curiosa invención,

he elegido yo

alguno en que pueda el chiste

unirse a la diversión.

Yo os llamo, os busco, venid a mi voz.

Entretenga el artificio

la vaga memoria del próximo horror,

y no pueda, no,

malquistar la vecindad

aplausos de la razón.

Yo os llamo, yo os busco, venid a mi voz.

¿Quién diremos?

El respeto.

Sepamos quién es.

Amor.

Diga el nombre.

Ingratitud.

¿Qué gente?

La sinrazón.

¿Quién es?

La desconfianza.

Descubra el rostro.

El favor.

¿Quién va allá?

El olvido.

¿Hay más?

No, que para tu intención...

... basta un respeto que viste

su afecto de su temor.

Un amor a quien le encienden

soplos de la inclinación. 


$\begin{array}{ll}\text { LA DESCONFIANZA.- } & \begin{array}{l}\text { Una desconfianza aleve, } \\ \text { comunera del amor. }\end{array} \\ \text { LA INGRATITUD.- } & \begin{array}{l}\text { Una ingratitud esmalte } \\ \text { propio de la perfección. }\end{array} \\ \text { EL OLVIDO.- } & \begin{array}{l}\text { Un olvido contrapuesto } \\ \text { carámbano de su ardor. }\end{array} \\ \text { LA SINRAZÓN.- } & \begin{array}{l}\text { Una sinrazón castigo } \\ \text { de su misma sinrazón. }\end{array} \\ \text { EL FAVOR.- } & \begin{array}{l}\text { Un favor, hijo bastardo } \\ \text { de la villa donde son }\end{array} \\ & \text { los primores, solo ser } \\ \text { antípodas del primor. } \\ \text { Y aun sobra, que no lo diré } \\ \text { por tanto. Y pues a mi voz } \\ \text { vinisteis a divertir } \\ \text { la entretenida estación } \\ \text { del día, sabed que os tengo } \\ \text { prevenido un ruego, por } \\ \text { que despierte a la alabanza } \\ \text { el mundo de la invención. }\end{array}$

TODOS.-

LA DIVERSIÓN.-

EL AMOR.¿Cuál es?

Aquel, aquel idioma de los muchachos llamo, el de vuelen pajaritos. Refiérenos, diversión, en qué consiste.

LA DIVERSIÓN.- $\quad$ En que cuando cantando dijere yo que vuele cosa de quien se apropia el volar, veloz cada uno ha de levantar los brazos para la acción del vuelo. Y cuando no pueda volar lo nombrado, no; pagare una prenda quien sin ocasión levantó los brazos, o no los supo levantar con ocasión.

TODOS.Está bien. Vamos jugando. LA DIVERSIÓN.- $\quad$ Pues porque se logre con más vista, juéguese en pie, entreteniendo el primor de los lazos con la dulce lisonja de la canción. 
TODOS.-

OTROS.-

LA DIVERSIÓN.TODOS.-

Todos ala.

LA DIVERSIÓN.-

LOS CUATRO.-

LA DIVERSIÓN.-
Vamos de esta.

$\mathrm{Y}$ quien cayere

entregue prenda.

A eso voy.

Cuidado, que todo es

menester donde hay amor.

Levantan todos los brazos.

EL RESPETO y

LA INGRATITUD.-

LA DIVERSIÓN.-
Es este rapaz vendado

tormento tan no entendido,

que en las sombras del olvido

arde otro nuevo cuidado.

Y pues, airado,

escarmentar no saben

mis devaneos...

Vuelen, vuelen.

Que vuelan.

¡Vuelen deseos!

\section{TODOS.- \\ LA DIVERSIÓN.- \\ para en adelante, que \\ ahora no fue mucho. \\ ¿Por qué no? \\ (Canta.) \\ Porque aunque más remiso \\ sea un afecto, \\ no hay acción tarda cuando \\ vuela el deseo.}

Juntanse ya las esquinas.

LA DESCONFIANZA.- Pues se han de alternar las coplas, yo me sigo.

EL OLVIDO.- $\quad$ Sinrazón, ojo alerta.

LA SINRAZÓN.- C Cuanto diera

porque cayese el favor.

LA DESCONFIANZA.- (Canta.)

Quien desconfía es testigo

de cuánto ensalza al desdén, 


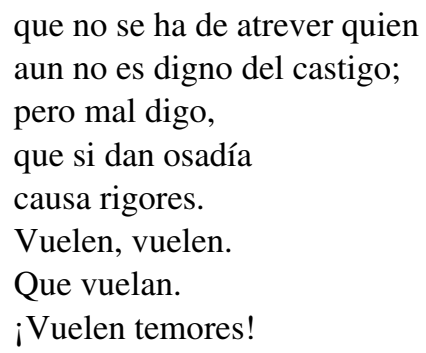

Están quietos todos con los brazos menos LA SINRAZÓN.

EL RESPETO.-

LA DIVERSIÓN.-

LA INGRATITUD.-

EL FAVOR.-

LA INGRATITUD.-

LA DIVERSIÓN.-

LA SINRAZÓN.-
La sinrazón ha movido los brazos.

Sí, pues perdió.

El respeto no es testigo válido...

... de la razón.

(Canta.)

Porque, en amor, reñidos

sobre sus con qués

andan siempre respetos

y sinrazones.

No obstante, ha de entregar prenda

en muestras de que perdió,

sinrazón que intenta un vuelo

a la vista de un temor.

Esta cinta celeste

por prenda entrego,

que no puede ser de otro

si dice celos.

Échanlos de en medio por de fuera, y dos alas.

LA INGRATITUD.- $\quad$ Lo ingrato, si sufre el ruego

es para doblar empresas,

pues estorba las pavesas

quien no deja arder el fuego;

pues si al despego

baja en polvos incendio

que sube en tiros.

Vuelen. Vuelen.

TODOS.-

Que vuelan.

LA INGRATITUD.- $\quad$ Vuelen, suspiros.

Levantan todos los brazos menos LA DESCONFIANZA. 


\begin{tabular}{|c|c|}
\hline EL FAVOR.- & $\begin{array}{l}\text { La desconfianza pierde, } \\
\text { pues siendo el suspiro voz } \\
\text { que vuela, no ha levantado } \\
\text { los brazos. }\end{array}$ \\
\hline EL OLVIDO.- & $\begin{array}{l}\text { Dice el favor } \\
\text { muy bien. }\end{array}$ \\
\hline LA DESCONFIANZA.- & $\begin{array}{l}\text { Que era } \\
\text { acción de volar, mas yo } \\
\text { pensé que ella lo había dicho } \\
\text { callando. }\end{array}$ \\
\hline EL AMOR.- & ¿De la razón? \\
\hline LA DESCONFIANZA.- & $\begin{array}{l}\text { Porque, si yo soy madre } \\
\text { de los discretos, } \\
\text { ya se sabe que siempre } \\
\text { suspiro a tiempo. }\end{array}$ \\
\hline EL AMOR.-- & En todo caso, de prenda... \\
\hline LA DESCONFIANZA.- & $\begin{array}{l}\text { Este desengaño doy, que } \\
\text { traigo en el muelle. }\end{array}$ \\
\hline LA DIVERSIÓN.- & $\begin{array}{l}\text { Venga, } \\
\text { por ser joya de valor. } \\
\text { (Canta.) } \\
\text { Y porque no hay quien sufra, } \\
\text { no siendo necio, } \\
\text { una desconfianza } \\
\text { puesta al espejo. }\end{array}$ \\
\hline
\end{tabular}

Cruzado dobles.

EL AMOR.-

Vaya esta copla, no mas, para ir dando prendas.

LA DIVERSIÓN.- $\quad$ Soy contenta.

EL OLVIDO.- $\quad$ Si salgo de esta, le doy mil gracias a Dios.

LA SINRAZÓN.- Hizo amor a la belleza mudable para más daños, que no valen desengaños si es hermosa una fineza. Y pues empieza así a alentar Cupido las esperanzas, vuelen, vuelen.

TODOS.¡Que vuela!

Levantan todos los brazos menos El RESPETO, EL AMOR y LA INGRATITUD. LA SINRAZÓN.- $\quad$ Vuelen mudanzas. 
EL OLVIDO.-

LOS TRES.-

EL OLVIDO.-

EL RESPETO.-

EL FAVOR.-

EL AMOR.-

UNOS.-

OTROS.-

EL OLVIDO.-

EL AMOR.-

EL FAVOR.-
(Al RESPETO, EL AMOR y LA INGRATITUD.)

Ustedes pierden.

¿Por qué?

Porque ninguno cumplió

con la acción de volar.

¿Luego

vuelan mudanzas de amor?

Sin respeto.

Tú te engañas.

Yo digo bien.

Yo mejor.

Pluma es cualquiera mudanza.

Qué importa eso, si en rigor

no puede cortar el aire

con el peso del arpón.

Viento

es toda veleidad,

y prueba la conclusión

el que ella hace volar, sí,

pero que ella vuele, no.

LA DESCONFIANZA.- $\quad$ La mudanza, a quien alas

dan mis sollozos,

muda esfera al aliento

de cualquier soplo.

LA INGRATITUD.- $\quad$ Si es fija en ser mudable, ¿quién no asegura

que la firma el impulso

de quien la muda?

LA DIVERSIÓN.-

LA SINRAZÓN.-

LA DIVERSIÓN.-

TODOS.-

LA DIVERSIÓN.-
La mudanza, aire y tierra

retrata a un tiempo,

pues por doblar engaños

muda elementos.

Señores, dense por buenos.

Pues el cristal que me dio

la desconfianza, vuelva

a sus manos, y el listón

a las tuyas.

¿Con qué pena?

Con la que de su favor

alcance perdón, si hay

a tanto yerro perdón.

Fiaremos diciendo a un tiempo

lo dulce de nuestra voz.

Por de fuera, hay ala. 
LA DIVERSIÓN y

LA INGRATITUD.- - (A dúo.)

Censura en los asuntos

de los sainetes,

algo a lo discursivo

supla lo estéril.

FINIS

BAILE DE VENENO DE LOS SENTIDOS

Margarita Ruano, año 1700.

PERSONAJES: Paula. Manuela. Laura. Fabio (Cisneros.) Silvio (Cabaña.)

Salen PAULA y MANUELA, cada una por su lado, cantando.

$\begin{array}{ll}\text { PAULA.- } & \text { De Lisi, divina, } \\ & \text { adoro el rigor } \\ & \text { sin esperanzas. } \\ & \text { Más tengo mi amor } \\ & \text { con fe peregrina, } \\ & \text { pues es noble afecto } \\ & \text { arder mariposa } \\ & \text { en tu sacro respeto. } \\ & \text { De Lisi, los rayos, } \\ & \text { mi infeliz amor. } \\ & \text { Qué sombra se ostenta } \\ & \text { de su resplandor } \\ \text { MANUELA.- } & \text { en tristes desmayos. } \\ & \text { Sigue mi fineza, } \\ \text { que en vivos desdenes } & \text { humilde tropieza. } \\ & \text { (Repita.) } \\ \text { ¿Mas, qué es lo que miro, penas? } & \text { ¿Qué es lo que miro, pesares? } \\ \text { ¿No es Fabio el que allí he mirado? } & \text { ¿No es Silvio el que hacia esta parte } \\ \text { viene? } & \text { Iras disimulemos. } \\ \text { Disimulemos pesares. } \\ \text { ¿Dónde Silvio por aquí? } \\ \text { MAULA.- } & \text { Y mal sino, que nos trae } \\ \text { PAULA.- } & \text { una misma causa a entrambos, } \\ \text { MANUELA.- } & \end{array}$


PAULA.-

MANUELA.-

PAULA.- pues las luces celestiales idolatramos de Lisi.

Mas, tan en vano, que el aire solo escucha nuestra voces, pues es roca incontrastable de nuestra porfía al ruego. Ya sí, compitiendo en balde sin envidias de dichoso, está nuestro duelo amante. Por esta selva me han dicho de su estampa las señales que ha pasado. Pues las flores respiran olor fragante.

Y si no miente el deseo, entre aquellos arrayanes está en los brazos del sueño cautivando libertades.

Descúbreselo. Sepa a LAURA en un peñasco.

MANUELA.-

PAULA.-

MANUELA.PAULA.A DÚO.-
Divino. Imposible. Hermoso. ¿Es posible que descanses de aprisionar albedríos y sujetar voluntades? ¿Quién no se llega a abrazar en tus luces celestiales, si el incendio con que hielas es la nieve con que ardes? Pero publiquen mis ansias. Digan mis ansias amantes. Hechizo de los sentidos, que con lisonjas mortales compones de tiranías tus fingidas suavidades. Lisonja del cautiverio, en cuya dichosa cárcel la libertad es prisión y el albedrío es rescate.

No prosigas. Suspende tu curso.

Tus clausulas callen, $y$ al Imperio de quien obedeces no respires, no alientes, no inquietes el aire. 
LAURA.-

PAULA.-

MANUELA.-

LAURA.-
¿Quién de mi altivez? ¿Qué es esto?

¿Cómo aleves profanasteis

del sobio de mi respeto

los venerados umbrales?

Una fineza te enoja.

Un afecto noble.

Baste,

que se quejará el oído

de que pudieron causarle

impresión de afecto indigno

vuestras lisonjas cobardes.

Salen CISNEROS y CABAÑA.

CISNEROS.-

CABAÑ.-

LOS DOS.-

PAULA.-

MANUELA.-

LAURA.-

PAULA.-

MANUELA.-
A los ecos de tus voces, a los afectos que esparce vuestra queja...

...hemos venido.

Yo cuando, sí, qué pesares.

Pues yo, sí, tú, cuándo, ya.

Yo.

Apuntador, ¿qué hace

que no apunta?

Denos versos.

Miran detrás de la cortina y no está el apuntador. Y hay en el suelo un papel en blanco.

LAURA.-

PAULA.-

CISNEROS.-

CABAÑ.-

MANUELA.-

PAULA.-

MANUELA.-

TODAS.-

A CUATRO VOCES.-
Más qué es esto, aquí no hay nadie.

En el suelo está un papel.

Mira si acaso es el baile.

¡Qué baile! que aquí no hay nada

escrito.

Verlo es en balde,

que está en blanco.

Y el remedio,

en caso tan importante,

es que supla aquesta falta

(que hoy sin ejemplar se hace)

auditorio tan ilustre...

Diciendo, por si obligarle

podemos a la piedad...

Como en las loas se hace.

Silencio, señores, escuchen por Dios

Quedito, pasito, no haya rumor

si la música sonora

divierte vuestra atención, 


\author{
y en acorde suspensión \\ de cláusulas se mejora, \\ perdonad, que por ahora \\ el baile acabe, diciendo el rumor \\ no chiste, el murmullo, si calla el clamor. \\ $\mathrm{Y}$ si es que apacibles llegamos a veros, \\ alegres diremos, a los mosqueteros, \\ silencio, señores, que el baile acabó. \\ FINIS
}

BAILE DE LOS TÍTULOS DE COMEDIAS

Margarita Ruano. Madrid, 30 de marzo de 1690.

PERSONAJES: Muchacha. Bernarda. Manuela. María. José. Teresa.

MUCHACHA.-

(Dice dentro, a la música.)

Con títulos conocidos

de muchas comedias viejas,

si no por nuevo, por otro,

un sainete se os presenta:

primera y segunda parte

hubo, y la tercera es esta;

o si fuera del contrato,

del contento la tercera.

Sale BERNARDA.

BERNARDA.-

Pues en Madrid, por dentro, cada loco con su tema dice, al darnos ocasión, industrias contra finezas.

Sale MANUELA.

MANUELA.-

Pues veis lo que son, mujeres,

en los juegos de la aldea

obras con trampa, adelante:

el laberinto de Creta.

BERNARDA.-

¿Quién cegara al mentiroso?

MANUELA.-

Los encantos de Medea.

¿...?.-

A un encanto, otro mayor.

MANUELA.-

La culpa busca la pena.

BERNARDA.-

Pues abrir el ojo. 
MANUELA.-

BERNARDA.-

MANUELA.-

BERNARDA.-

MANUELA.-

BERNARDA.-

MANUELA.-

BERNARDA.-

MANUELA.-

MARÍA.-

MANUELA.-

JOSÉ.-

TERESA.-

BERNARDA.-

MANUELA.-

BERNARDA.-

MARÍA.-

MANUELA.-

JOSÉ.-

MANUELA.-

BERNARDA.-

TERESA.-

MANUELA.-

BERNARDA.-

MANUELA.JOSÉ y TERESA.MANUELA.-
Quien

tiene enemigos no duerma.

Mentir o mudarse a un tiempo.

Cautela contra cautela.

Escúcheme el caballero.

¿Qué quiere la hermosa fea?

Siempre es la fe en el ingrato

ofender con las finezas.

¡Que me siga!

Allá dará el rayo.

La razón no quiere fuerza.

¿Quién soy?

Primero soy yo:

La cisma de Ingalaterra.

Mece.

Soy Pascual el ciego.

Ciego, es san Francisco de Sena.

Soy Roberto el Diablo.

Más

mal hay en el aldehuela.

Siendo Psiquis y Cupido,

seamos Dido y Eneas.

Es el mayor imposible

oponerse a las estrellas.

La mentirosa verdad

parece la rica hembra.

La verdad en el engaño

adelgaza, más no quiebra.

En mí hallara el pastor Fido

la serrana de la Vera.

Y en mí el amor bandolero

el servir con mala estrella.

La señora y la criada...

amor y obligación muestran.

Afectos de odio y amor

la ignorante y la discreta.

Estudiosa soy, Laura.

Yo la dama boba.

Tenga

la cueva de Salamanca.

Usted, usted las Vatuecas.

Dineros son calidad.

Pues pobreza no es vileza.

Quien se muda Dios le ayuda.

No hay mal que por bien no venga. 


\begin{tabular}{|c|c|}
\hline BERNARDA.- & $\begin{array}{l}\text { Amado y aborrecido } \\
\text { el desengaño a su tiempo } \\
\text { tendrá, con dar tiempo al tiempo, } \\
\text { el astrólogo fingido. }\end{array}$ \\
\hline MANUELA.- & $\begin{array}{l}\text { Como soy el loco cuerdo, } \\
\text { fingir y amar no rehúso, } \\
\text { pues sé que el amor al uso } \\
\text { fue siempre el mejor acuerdo. }\end{array}$ \\
\hline MARÍA.- & $\begin{array}{l}\text { Yo escojo del mal en menos; } \\
\text { la amistad vence al rigor, } \\
\text { que amor vencido de amor } \\
\text { me trae a servir a buenos. }\end{array}$ \\
\hline MANUELA.- & $\begin{array}{l}\text { Travesuras de Roldán. } \\
\text { Dicen que no puede ser, } \\
\text { la más constante mujer, } \\
\text { la esclava de su galán. }\end{array}$ \\
\hline JOSÉ.- & $\begin{array}{l}\text { Como amante y como honrada } \\
\text { los milagros del desprecio } \\
\text { siente en la dicha del necio } \\
\text { la más perfecta casada. }\end{array}$ \\
\hline MANUELA.- & $\begin{array}{l}\text { Amor no es amor sin celos. } \\
\text { Bueno es guardar y guardarse, } \\
\text { que es casarse por vengarse } \\
\text { ser los novios de hornachuelos. }\end{array}$ \\
\hline BERNARDA.- & $\begin{array}{l}\text { El melancólico pudo } \\
\text { engañar para reinar. }\end{array}$ \\
\hline MANUELA.- & $\begin{array}{l}\text { Mi reina, vasta callar, } \\
\text { yo soy el amante mudo. }\end{array}$ \\
\hline MARÍA.- & $\begin{array}{l}\text { A un tiempo rey y vasallo } \\
\text { fuera el príncipe constante. }\end{array}$ \\
\hline MANUELA.- & $\begin{array}{l}\text { Soy el príncipe ignorante; } \\
\text { niña peor es orgullo. }\end{array}$ \\
\hline JOSÉ.- & $\begin{array}{l}\text { La más dichosa venganza } \\
\text { del pan y del palo espere. }\end{array}$ \\
\hline MANUELA.- & $\begin{array}{l}\text { Ha de ser lo que Dios quiere, } \\
\text { solo en Dios la confianza. }\end{array}$ \\
\hline TERESA.- & $\begin{array}{l}\text { El negro del mejor amo } \\
\text { será siendo el Saladino. }\end{array}$ \\
\hline MANUELA.- & $\begin{array}{l}\text { ¿Yo negro? Eso a Juan Latino, } \\
\text { que yo Lorenzo me llamo. }\end{array}$ \\
\hline TERESA.- & $\begin{array}{l}\text { Al picarito en España } \\
\text { porfiando vence amor. }\end{array}$ \\
\hline MANUELA.- & $\begin{array}{l}\text { Travesuras son valor; } \\
\text { soy el Hércules de Ocaña. }\end{array}$ \\
\hline MARÍA.- & $\begin{array}{l}\text { De elegir al enemigo } \\
\text { lo que se usa nos escusa. }\end{array}$ \\
\hline
\end{tabular}


La misma conciencia acusa, la traición busca el engaño.

BERNARDA.-

MANUELA.-

JOSÉ.-

MANUELA.-

TERESA.-

MANUELA.-

MARÍA.-

MANUELA.-

BERNARDA.-

MANUELA.-

TODAS.-

MANUELA.-

TODAS.-

MANUELA.-

TODAS.-

MANUELA.-

TODOS.-
$\mathrm{Su}$ yerro es el parecido

al yerro del entendido.

Vencerse es mayor valor

de el acaso y el error.

Cargan de el galán sin dama

los desprecios en quien ama.

Caer para levantar

es la gala del nadar...

Quiere amor enamorado

pedir justicia al culpado.

En la fuerza de la Ley,

el mejor alcalde, el Rey.

En la fuerza lastimosa

yo haré la prisión dichosa.

Al poder de la amistad

siempre ayuda la verdad.

La presumida y la hermosa

logren la deshonra amorosa.

Y Amar sin saber a quien

el desdén con el desdén.

Será el baile el encubierto.

No siempre lo peor es cierto.

¿Es bueno?

A la sebera

¿Y si es malo?

Ello dirá.

¿Es bueno? A la sebera,

y si es malo ello dirá.

\section{FINIS}

\section{BiBLIOGRAFÍA}

\section{Manuscritos}

Vayle de los títulos de comedias, de Margarita Ruano. Madrid, 30 de marzo de 1690. Manuscrito de 4 hojas en $4^{\circ}$, de 1690. [En la Biblioteca Nacional de España: MSS 14513/75]

Baile de las posadas de Madrid, de Margarita Ruano, 1692. Manuscrito de 7 hojas en $4^{\circ}$, de 1692. [En la Biblioteca Nacional de España: MSS 14513/72]

Baile del Juego de Buelen Pajaritos, de Margarita Ruano, 1692. Manuscrito de 5 hojas en $4^{\circ}$, de 1692. [En la Biblioteca Nacional de España: MSS 14514/9]

Baile de beneno de los sentidos. Manuscrito de 3 hojas en $4^{\circ}$, letra del siglo XVII, fechado en 1700. [En la Biblioteca Nacional de España: MSS 14513/58] 


\section{Estudios y ediciones}

Escabias, Juana. (2013) Dramaturgas del Siglo de Oro. Guía Básica. Madrid: Huerga y Fierro Editores.

Ruano, Margarita. (1928) Baile de las posadas de Madrid (pp.4-9) en «El Madrid de Calderón», de Miguel Herrero García (ed.) Revista de la Biblioteca, Archivo y Museos, año V, n. ${ }^{\circ}$ XVII. Madrid: Ayuntamiento de Madrid, 1928, pp. 1-18.

Herrero García, Miguel. (1926) El Madrid de Calderón: textos y documentos. Madrid: Imprenta Municipal, 1926.

Hormigón, Juan Antonio (dir.) (1996) Autoras en la Historia del Teatro Español (1500-1994).

Madrid: Asociación de Directores de Escena. Volumen I, pp. 595-596. 